\title{
FRAMING DEVICE IN GAMSON AND MODIGLIANI MODEL ABOUT THE NEWS OF KOMISI PEMBERANTASAN KORUPSI
}

\section{PERANGKAT FRAMING MODEL GAMSON DAN MODIGLIANI TENTANG PEMBERITAAN KOMISI PEMBERANTASAN KORUPSI}

\author{
Ratih Putri Febriana $^{1 *}$, Sukarelawati ${ }^{2}$, Maria Fitriah ${ }^{3}$ \\ ${ }^{123}$ Program Studi Sains Komunikasi, Fakultas Ilmu Sosial dan Ilmu Politik, Universitas Djuanda Bogor
} Jl. Tol Ciawi No. 1 kotak Pos 35, Bogor 16740

*Korespondensi: Ratih Putri Febriana, ratihputrif@gmail.com

(Diterima oleh Dewan Redaksi: 12 Juni 2020)

(Dipublikasikan oleh Dewan Redaksi: 5 Oktober 2020 )

\begin{abstract}
Firli Bahuri's election as chairman of Komisi Pemberantasan Korupsi, and efforts to revise the laws of anti-corruption Commission triggered the noise, the media have a responsibility to tell it. Each media has constructed the news of KPK with differently. The problem in this study is "How does the framing device in Gamson and Modigliani model about the news of Komisi Pemberantasan Korupsi on the headline of Tempo Magazine 4524/16-22 September, 2019 edition?". This study aims to know the framing device in Gamson and Modigliani model about the news of Komisi Pemberantasan Korupsi on the headline of Tempo Magazine 4524/16-22 September, 2019 edition. The study uses a qualitative approach with constructionist paradigm, the method this study uses framing analysis of Gamson and Modigliani, the primary data obtained by documentation techniques and secondary data obtained from the library research. The results showed, Tempo used the framing device for contructed the bad news model. "Hidup-Mati Komisi Antikorupsi" and "Jendral Polisi Sarat Kontroversi" articles have fulfilled all the elements in the framing device, but "Batal Istana Koreksi Hasil Seleksi" article does not fulfilled one of of the elements, that is metaphors.
\end{abstract}

Keywords: Framing Device; Gamson and Modigliani Model; The News of Komisi Pemberantasan Korupsi; Tempo Magazine. 


\begin{abstract}
ABSTRAK
Terpilihnya Firli Bahuri sebagai ketua Komisi Pemberantasan Korupsi, dan upaya merevisi undang-undang komisi antikorupsi memicu kegaduhan, media memiliki tanggung jawab untuk memberitakannya, masing-masing media mengkonstruksikan pemberitaan Komisi Pemberantasan Korupsi secara beragam. Masalah dalam penelitian ini adalah "bagaimana perangkat framing model gamson dan modigliani tentang pemberitaan Komisi Pemberantasan Korupsi pada laporan utama majalah Tempo edisi 4524/16-22 september 2019?". Penelitian ini bertujuan untuk mengetahui perangkat framing model gamson dan modigliani tentang pemberitaan Komisi Pemberantasan Korupsi pada laporan utama majalah Tempo edisi 4524/16-22 september 2019?". Penelitian ini menggunakan pendekatan kualitatif paradigma konstruksionis, dengan metode analisis framing Gamson dan Modigliani, data primer diperoleh dengan teknik dokumentasi dan data sekunder diperoleh dengan studi pustaka. Hasil penelitian menunjukan, perangkat framing yang digunakan Tempo membentuk konstruksi citra model bad news. Artikel "Hidup-Mati Komisi Antikorupsi" dan "Jendral Polisi Sarat Kontroversi" telah memenuhi seluruh elemen dalam perangkat framing, namun artikel "Batal Istana Koreksi Hasil Seleksi" tidak memenuhi salah satu elemen, yaitu metafora.
\end{abstract}

Keywords: Perangkat Framing; Model Gamson dan Modigliani; Pemberitaan Komisi Pemberantasan Korupsi; Majalah Tempo.

Ratih Putri Febriana, Sukarelawati, Maria Fitriah 2020. Perangkat Framing Model Gamson Dan Modigliani Tentang Pemberitaan Komisi Pemberantasan Korupsi. Jurnal Komunikatio: 6 (2): 47-58.

\section{PENDAHULUAN}

Sejak dibentuk pada tahun 2002, Komisi Pemberantasan Korupsi (KPK) telah mengalami empat kali pergantian pimpinan. Pada 12 September 2019, Dewan Perwakilan Rakyat (DPR) melaksanakan forum lobi dan memilih lima nama komisioner KPK periode 2019-2023. Nama-nama tersebut adalah Lili Pintauli Siregar, Nawawi Pomolango, Nurul Gufron, Alexander Marwata, dan Inspektur Jenderal Firli Bahuri. Inspektur Jenderal Firli Bahuri terpilih sebagai ketua Komisi Pemberantasan Korupsi dengan dukungan bulat anggota Komisi Hukum DPR (Trianita, 2019: 74). Bersamaan dengan hal itu, Presiden Jokowi menyetujui revisi Undang-undang KPK.

Terpilihnya Firli sebagai ketua KPK, dan upaya merevisi undang-undang komisi antikorupsi membuat pimpinan KPK bereaksi keras (Ferdianto dkk, 2019: 73). Sebelum disahkan, KPK sendiri menolak revisi Undang-undang KPK dengan salah satu pertimbangan berupa terancamnya independensi KPK. Penolakkan ini diunggah oleh KPK pada akun instagram @official.kpk pada 6 September 2019.

Selain KPK sendiri, penolakan juga muncul dari berbagai kalangan masyarakat. Seperti aksi di Gedung Merah Putih KPK, dimana masa aksi merupakan dari pegiat antikorupsi dan pegawai KPK pada 17 September 2019. Selain itu di Yogyakarta, mahasiswa menginisiasi aksi dengan mengusung tagar \#GejayanMemanggil dan Aliansi Rakyat bergerak, menolak segala upaya pelemahan pemberantasan korupsi, pada 23 dan 30 September 2019, berpusat di Gejayan. Mahasiswa yang tergabung dalam Aliansi Badan Eksekutif Mahasiswa Seluruh Indonesia juga melaksanakan Aksi Nasional (Aknas) dengan mengusung tagar \#tuntaskanreformasi di depan gedung DPR RI pada 23 dan 24 September 2019 dengan salah satu tuntutannya adalah restorasi upaya pemberantasan korupsi, kolusi dan 
nepotisme, jangan lemahkan KPK, tindak tegas koruptor.

Korupsi, merupakan tindak pidana luar bi asa (extra ordinary crime), sehingga hal-hal terkait KPK menjadi poros perhatian publik, di sini merupakan letak penting dari media. Pada hal ini, menurut Kovach dalam Ramandita dan Yuliana (2018: 16) media juga perlu memiliki loyalitas pada warga serta selalu memberikan informasi yang dibutuhkan oleh masyarakat, terlebih berkaitan dengan kesejahteraan publik.

Pemberitaan media mengenai topik KPK dikonstruksikan secara beragam. Mengetengahkan perbedaan ini, tentu bukan menekankan bias atau distorsi dari pemberitaan suatu media. Ini dipaparkan untuk memberikan ilustrasi bagaimana berita yang kita baca tiap hari telah melalui proses konstruksi (Eriyanto, 2012: 3). Salah satu media yang menerbitkan pemberitaan mengenai KPK adalah majalah Tempo.

Berita merupakan sebuah bentuk konstruksi dari realitas yang di konstruksikan oleh seorang jurnalis. Menurut Vardiansyah dan Febriani (2018: 95), berita dimaknai sebagai konstruksi atas realitas.

Konstruksi yang dibangun akan memberikan efek kepada publik. Ketika seseorang menyimak suatu wacana dalam surat kabar atau televisi, secara tidak sadar seseorang tersebut sedang digiring pada definisi yang di tanamkan oleh media massa. Hal itu dapat membuat seseorang tersebut mengubah definisi mengenai realitas sosial atau memperteguh asumsi yang telah dimiliki sebelumnya. Goffman dalam Sobur (2015: 162) mengandaikan frame sebagai kepingan-kepingan perilaku (strips of behavior) yang membimbing individu dalam membaca realitas.

Berdasarkan uraian di atas, maka dapat diambil rumusan masalah yaitu: "bagaimana perangkat framing model gamson dan modigliani tentang pemberitaan Komisi Pemberantasan
Korupsi pada laporan utama majalah Tempo edisi 4524/16-22 september 2019?"

\section{MATERI DAN METODE}

\section{MATERI}

\section{Komunikasi Massa}

Menurut pendapat Ardianto dkk (2017: 3) definisi komunikasi massa yang paling sederhana dikemukakan oleh Bittner, yakni: komunikasi massa adalah pesan yang dikomunikasikan melalui media massa pada sejumlah besar orang (mass communication is messages communicated through a mass medium to a large number of people). Berdasatkan definisi tersebut diketahui bahwa komunikasi massa harus menggunakan media massa. Meskipun sebenarnya komunikasi disampaikan kepada khalayak banyak.

\section{Perangkat Framing Model Gamson dan Modigliani}

Hal yang paling penting adalah mengemas berita atau dengan kata lain framing, Maka berita itu harus dikonstruksi sedemikian rupa dibentuk dengan baik, agar konstruksi pesan itu dimaknai oleh audiens (Tamburaka, 2012: 140). Elnawawy dan Elmasry (2017: 1809) memaparkan, some of the framing differences can be attributed to the different nature of the events (beberapa perbedaan pembingkaian dapat dikaitkan dengan perbedaan peristiwa yang sebenarnya).

El-nawawy dan Elmasry (2017: 1809) memaparkan, some of the framing differences can be attributed to the different nature of the events (beberapa perbedaan pembingkaian dapat dikaitkan dengan perbedaan peristiwa yang sebenarnya).

Rumusan atau model Gamson dan Modigliani didasarkan pada pendekatan konstruksionis yang melihat representasi media-berita dan artikel, terdiri atas package interpretatif yang mengandung konstruksi makna tertentu. Di dalam package ini terdapat dua struktur yaitu core frame dan condensing symbol. Struktur 
pertama merupakan pusat organisasi elemen-elemen ide yang membantu komunikator untuk menunjukan substansi isu yang tengah dibahas. Sedangkan struktur kedua mengandung dua substruktur yaitu framing device dan reasoning device (Sobur, 2015: 177).

Core frame (gagasan sentral) berisi elemen-elemen inti untuk memberikan pengertian yang relevan terhadap peristiwa, dan mengarahkan makna isuyang dibangun condensing symbol (simbol yang "dimampatkat"). Eriyanto (2012: 263) menjelaskan ide sentral ini akan didukung oleh perangkat wacana lain sehingga antara satu bagian wacana dan bagian lain saling kohesif (saling mendukung).

Struktur framing device (perangkat framing) yang mencakup metaphor (metafora), exemplar (ilustrasi), catchphrases (kontras), depictions (label), dan visual images (gambar visual) menekankan aspek bagaimana "melihat" suatu isu. Secara literal, metaphor dipahami sebagai cara memindah makna dengan merelasikan dua fakta melalui analogi, atau memakai kiasan dengan menggunakan kata seperti, ibarat, bak, sebagai, umpama, laksana. John Fiske dalam Sobur (2015: 179) menilai metafora sebagai common sense, pengalaman hidup keseharian yang di-taken-for-granted masyarakat. Common sense terlihat alamiah (kenyataan diproduksi secara arbitrer) dan perlahanlahan menjadi kekuatan ideologis kelas dominan dalam memperluas dan mempertahankan ide untuk seluruh kelas.

Exemplar mengemas fakta tertentu secara mendalam agar satu sisi memiliki bobot makna lebih untuk dijadikan rujukan/pelajaran. Catchphrases, istilah, bentukan kata, atau frase khas mencerminkan fakta yan merujuk pemikiran atau semangat tertentu. Depictions, penggambaran fakta dengan memakai kata, istilah, kalimat konotatif agar khalayak terarah ke citra tertentu. Visual images, pemakaian foto, diagram, grafis, tabel, kartun, dan sejenisnya untuk mengekspresikan kesan, misalnya perhatian atau penolakan, dibesarkan- dikecilkan, ditebalkan atau dimiringkan, serta pemakaian warna. Hornby dalam Tamburaka (2012: 146) juga menyebut kartun dimaksud adalah gambar lucu yang melukiskan kejadian-kejadian (biasanya politik) mutakhir dari suatu pemerintahan atau perilaku pejabat negara. Echol dalam Tamburaka (2012: 146) menyatakan dalam gambar tersebut biasanya memuat karikatur, gambar tiruan dari tokoh-tokoh yang terlibat dalam peristiwa yang dikartunkan itu.

\section{Majalah}

Secara historis, majalah adalah media alternatif sebagai penyalur suarasuara lain yang mengkritisi penyalah gunaan kekuasaan yang dilakukan oleh negara, karena ketundukan pada kepentingan pengusaha sehingga kesejahteraan rakyat semakin jauh dari harapan (Atmaja dan Ariyani, 2018: 110).

Majalah berita biasanya terbit setiap satu minggu satu kali, sehingga para wartawannya memiliki waktu yang cukup lama untuk memahami, menganalisis dan mempelajari suatu kejadian, dengan demikiam penyajian beritanya dapat dibahas secara lebih mendalam. Analisis beritanya dapat dipercaya dan didasarkan pada buku referensi yang relevan dengan suatu peristiwa. Kuncinya adalah, setiap berita dalam majalah disajikan lebih lengkap, karena dibubuhi latar belakang dari suatu peristiwa. Unsur why dikemukakan secara lengkap. Peristiwa atau proses terjadinya peristiwa (unsur how) dikemukakan secara kronologis (Ardianto, 2017: 121). Ciri khas majalah adalah posisinya sebagai jurnalisme interpretatif. Seperti yang dikemukakan Rivers dkk dalam Atmaja dan Ariyani (2018: 112), bagi malajalah, interpretasi justru menjadi sajian utama.

Selain menafsirkan berita, majalah juga sekaligus menjadi ajang diskusi secara berkelanjutan. Apabila ada masalah yang menarik dan baru diungkap sedikit dalam edisi sebelumnya, maka majalah dapat membahasnya secara berkelanjutan dan lebih mendalam pada edisi berikutnya 
selama tetap menarik bagi pembaca. Kajian terhadap masalah secara analisis mengakibatkan majalah menjadi rujukan sangat andal bagi aneka informasi dalam kehidupan sehari-hari. Dengan demikian, tidak mengherankan jika Rivers dkk dalam Atmaja dan Ariyani (2018: 112), menyatakan bahwa di atas semua itu fungsi terpenting majalah merupakan media penafsir terbaik.

Menurut Ardianto dkk (2017: 121), majalah merupakan media yang paling simpel organisasinya, relatif lebih mudah mengelolanya, serta tidak membutuhkan modal yang banyak. Sehinga, majalah juga dapat diterbitkan oleh kelompok masyarakat, di mana mereka dapat dengan leluasa dan luwes menentukan bentuk, jenis dan sasarannya. Meskipun sama-sama merupakan media cetak, majalah dapat dibedakan dengan surat kabar, karena majalah mempunyai karakeristik tersendiri.

\section{Dinamika Pemberitaan KPK}

Media cetak yang mempublikasikan pemberitaan mengenai KPK salah satunya adalah majalah Tempo dan FORUM Keadilan. Majalah Tempo edisi 4524/16-22 September 2019 yang memiliki judul "Janji Tinggal Janji”, dengan tiga laporan utama yaitu "Hidup-Mati Komisi Antikorupsi", "Jenderal Polisi Sarat Kontroversi", dan "Batal Istana Mengkoreksi Hasil Seleksi". Majalah FORUM Keadilan edisi 10 September 2019 yang memiliki judul "Firli Ketua KPK Saut Mundur", dengan forum utama berjudul "Ketua KPK Baru Pilihan DPR yang Ditolak".

Media online yang mempublikasikan pemberitaan mengenai KPK salah satunya adalah Kompas.com. Pada 14 September 2019 menerbitkan berita yang memiliki judul judul "Kisruh KPK: Pimpinan Merasa Tak Diajak Bicara dan Respons DPR". Selain Kompas.com, situs web KPK juga memuat berita tentang dirinya sendiri, salah satunya berjudul "10 Persoalan di Draft RUU KPK" yang diunggah pada 6 September 2019, dan berjudul "Rantai
Manusia Menjaga KPK" yang diunggah pada 11 September 2019.

\section{METODE}

Penelitian ini menggunakan pendekatan kualitatif paradigma konstruksionis, karena pada penelitian ini hanya terbatas pada bagaimana media massa mengkonstruksi atau membingkai beritanya. Adapun metode yang digunakan adalah metode analisis framing Gamson dan Modigliani. Unit analisis dari penelitian ini berupa setiap kata, kalimat, atau gambar yang mengandung makna pada laporan utama majalah Tempo edisi 4524/16-22 September 2019. Data dalam penelitian ini dikategorikan menjadi dua jenis, yaitu data primer dan sekunder. Data primer diperoleh dengan teknik dokumentasi dokumen publik. Dokumen publik tersebut adalah artikel berita pada laporan utama majalah Tempo edisi 4524/16-22 September 2019. Data sekunder diperoleh dengan studi pustaka. Studi pustaka dilakukan dengan mencari data dari jurnal ilmiah, buku-buku, serta bahan publikasi yang tersedia.

\section{HASIL DAN PEMBAHASAN}

\section{HASIL}

\section{Artikel berita 1: "Hidup-Mati Komisi Antikorupsi"}

Gagasan sentral dalam artikel berita ini berupa usia KPK yang sedang dipertaruhkan dan keterkaitan antara nama-nama komisioner dengan revisi Undang-Undang KPK. Perangkat framing yang digunakan Tempo untuk mengkonstruksi artikel berita ini adalah sebagai berikut:

a) Metafora

Terdapat dua metafora yang digunakan dalam artikel berita ini. Metafora yang pertama terdapat pada judul artikel berita itu sendiri, yaitu "Hidup-Mati Komisi Antikorupsi". Metafora yang kedua terdapat pada kalimat "Dia mengatakan lembaganya sedang di ujung tanduk".

b) Ilustrasi 
Ilustrasi yang terdapat dalam artikel berita "Hidup-Mati Komisi Antikorupsi merupakan kutipan dari ungkapan narasumber. Ungkapan narasumber tersebut secara langsung berisi ilustrasi yang mendukung gagasan sentral artikel berita tersebut. Artikel berita ini memberikan sebuah ilustrasi yang mana nama Firli Bahuri tidak memantik perdebatan. Dugaan terkait pelanggaran etik yang dilakukan oleh Firi Bahuri dianggap telah selesai karena telah lolos dari uji kelayakan oleh panitia seleksi (pansel).

c) Kontras

Kalimat atau frasa yang menonjol dalam artikel berita "Hidup-Mati Komisi Antikorupsi" adalah dikutipnya ungkapan dari komisioner KPK, Agus Rahardjo, "Ada yang terancam dengan keberadaan KPK".

d) Label

Artikel berita "Hidup-Mati Komisi Antikorupsi" memberi label pada nama Firli Bahuri dengan "tak memantik perdebatan". Padahal, nama Firli Bahuri tengah menyorot perhatian karena diduga telah melakukan pelanggaran etik berat.

e) Gambar visual

Pada artikel berita "Hidup-Mati Komisi Antikorupsi", terdapat dua penonjolan gambar visual. Gambar visual pertama, menunjukan papan perhitungan suara pemilihan komisioner $\mathrm{KPK}$, selain itu juga terdapat para anggota DPR yang sedang mengambil gambar papan perhitungan suara tersebut dengan menggunakan telepon

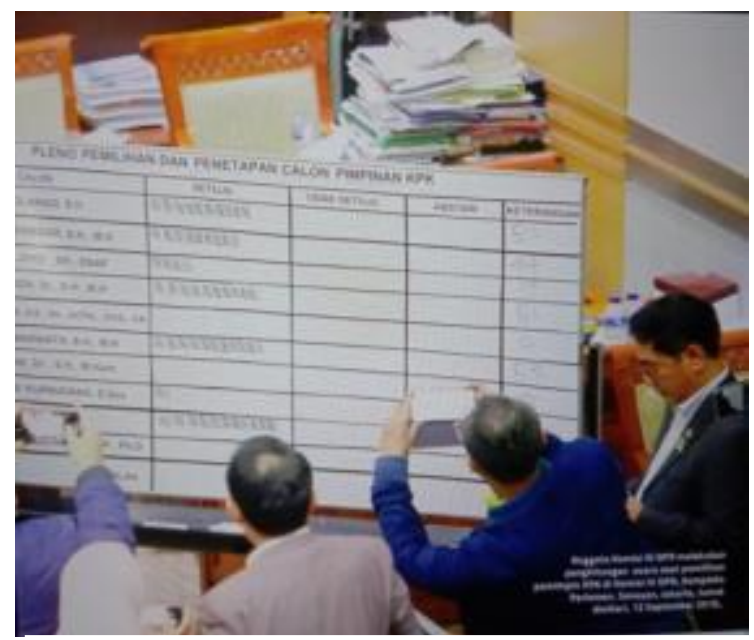

Gambar 1. Gambar Visual Artikel Berita "Hidup-Mati Komisi Antikorupsi" 1. genggam. Gambar visual tersebut diberi keterangan "Anggota Komisi III DPR melakukan penghitungan suara saat pemilihan pemimpin KPK di Komisi III DPR, Kompleks Parlemen, Senayan, Jakarta, Jumat dinihari, 13 September 2019."

Gambar visual kedua menampilkan Agus Rahardjo dan dua Wakil Ketua KPK sedang memberikan keterangan dengan wajah dan postur sedang bersedih. Gambar visual tersebut diberi keterangan "Ketua KPK Agus Raharjo bersama dua Wakil Ketua KPK, Saut Situmorang (kiri) dan Laode M. Syarif, memberikan keterangan tentang penyerahan mandat pimpinan, di Gedung KPK, Jakarta, 13 September 2019 (kanan)."

\section{Artikel berita 2: "Jendral Polisi Sarat Kontroversi"}

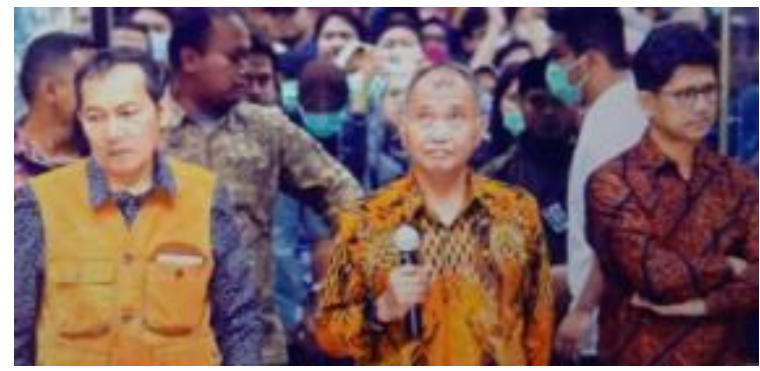

Gambar 2. Gambar Visual Artikel Berita "Hidup-Mati Komisi Antikorupsi" 2.

Gagasan sentral dalam artikel berita ini berupa Firli Bahuri menuai banyak kontroversi. Perangkat framing yang digunakan untuk mengkonstruksi artikel berita ini adalah sebagai berikut:

a) Metafora

Metafora dalam artikel berita ini mengutip ungkapan dari Hendro Pawond, yaitu "kami melakukan pengamanan." Kutipan ini dimaksudkan agar konstruksi citra mengenai sokongan pendukung terhadap kontroversi Firli Bahuri semakin terlihat kuat, karena selain mendapat dukungan dari anggota Dewan sejumlah kolegapun turut hadir untuk melihat uji kelayakan dan 
kepatutan Inspektur Jendral Firli Bahuri.

b) Ilustrasi

Jendral polisi sarat kontroversi ditekankan dalam artikel berita dengan melakukan ilustrasi. Artikel berita tersebut secara khusus memuat sebuah materi pertemuan Firli Bahuri dengan Ketua Umum Partai Demokrasi Indonesia Perjuangan (PDIP) beserta rombongannya. Ilustrasi ini dipilih bukan tanpa alasan. Pertemuan tersebut dinilai menimbulkan pertanyaan karena dalam pengakuan Firli Bahuri, kala itu sedang menghadiri perayaan ulang tahun Megawati, namun ulang tahun Megawati berbeda dengan waktu adanya pertemuan tersebut, yaitu 23 Januari.

c) Kontras

Kalimat atau frasa yang menonjol dalam artikel berita adalah "Menjadi kandidat yang sarat kontroversi, Inspektur Jendral Firli Bahuri terpilih sebagai Ketua Komisi Pemberantasan Korupsi". Kalimat tersebut merupakan kalimat yang menonjol sehingga menarik perhatian karena menekankan bahwa ketua KPK yang saat ini terpilih banyak menuai kontroversi.

d) Label

Tempo, memberi label pada tokoh Firli Bahuri berupa "Dekat dengan petinggi partai".

e) Gambar visual

Sesuai dengan judul artikel berita yang secara langsung menyebut tokoh Firli Bahuri dengan "Jendral

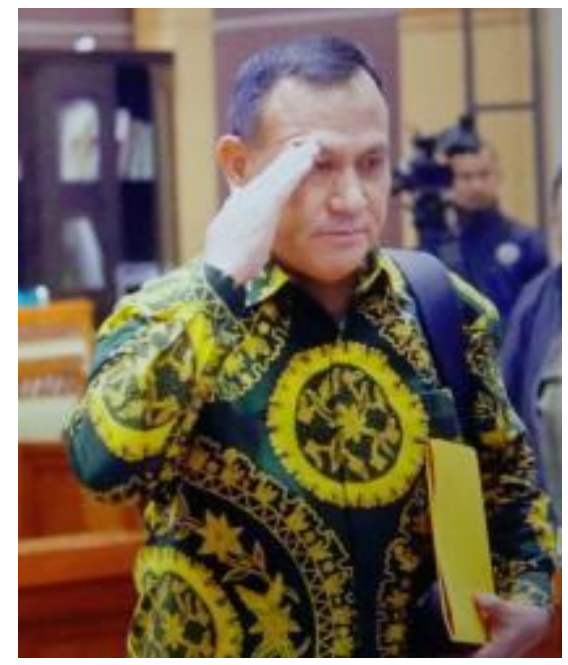

Gambar 3. Gambar Visual Artikel Berita "Jendral Polisi Sarat Kontroversi"
Polisi Sarat Kontroversi", gambar visual yang ditampilkan juga memuat gambar Firli Bahuri dengan keterangan: "Calon pemimpin Komisi Pemberantasan Korupsi, Firli Bahuri, setelah mengikuti uji kelayakan dan kepatutan di Komisi III DPR, Kompleks Parlemen, Senayan, Jakarta, 12 September 2019."

\section{Artikel berita 3: "Batal Istana Mengoreksi Hasil Seleksi”}

Gagasan sentral dalam artikel berita ini berupa Panitia Seleksi buru-buru mengumumkan sepuluh nama calon pimpinan KPK ke publik sehingga Presiden Jokowi batal meminta masukan masyarakat terkait nama-nama tersebut. Perangkat framing yang digunakan untuk mengkonstruksi arikel berita ini adalah sebagai berikut:

a) Metafora

Berdasarkan penelitian yang telah dilakukan, di dalam artikel berita ini tidak menggandung elemen metafora.

b) Ilustrasi

Artikel berita secara khusus memuat ungkapan Presiden Jokowi sebelum menggelar pertemuan tertutup dengan anggota Panitia Seleksi. Jokowi, kala itu sempat mengungkapkan akan meminta masukan dari para tokoh dan masyarakat atas hasil seleksi calon pimpinan KPK yang telah dilakukan Panitia.

c) Kontras

Kalimat atau frasa yang menonjol langsung terdapat pada judul artikel berita ini, yaitu "Batal istana mengoreksi hasil seleksi". Kalimat tersebut dipilih bukan tanpa alasan, melainkan untuk menekankan bahwa adanya penekanan dalam pembatalan niat Presiden Jokowi yang disebabkan oleh Panitia Seleksi buru-buru mengumumkan hasil seleksi. Sehingga mau-tidak mau presiden melayangkan 
surat pada DPR agar segera melakukan uji kelayakan dan uji kepatutan terhadap nama-nama calon pimpinan lolos seleksi.

d) Label

Tempo, memberi label pada Panitia Seleksi dengan menggunakan kalimat "Panitia seleksi buru-buru mengumumkannya ke publik".

e) Gambar visual

Sesuai dengan judul artikel berita yang membahas hasil seleksi, secara tidak langsung menekankan terkait Panitia Seleksi, meskipun di dalam judul tidak terdapat frasa "Panitia Seleksi". Maka, Tempo

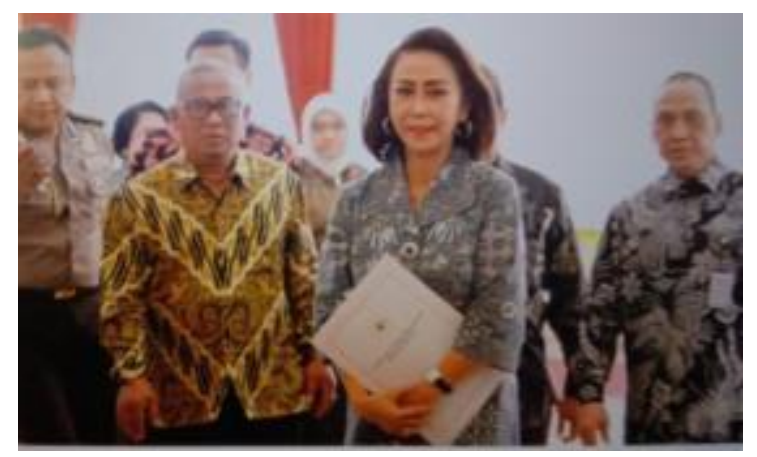

Gambar 4. Gambar Visual Artikel Berita "Batal Istana Mengoreksi Hasil Seleksi"

menampilkan gambar visual berupa potret Anggota Panitia Seleksi calon pimpinan KPK yang sedang mendekap map berwarna putih, di bawah gambar visual tersebut diberi keterangan: "Panitia Seleksi Calon Pimpinan KPK di Istana Merdeka, Jakarta, 2 September 2019."

\section{PEMBAHASAN}

Perangkat Framing Model Gamson dan Modigliani Tentang Pemberitaan Komisi Pemberantasan Korupsi Pada Laporan Utama Majalah Tempo Edisi 4524/16-22 September 2019

Tempo, dalam mengkonstruksikan artikel berita, telah menggunakan elemenelemen dalam perangkat framing model Gamson dan Modigliani. Konstruksi citra yang dibentuk oleh Tempo adalah model bad news, dimana Tempo mengkonstruksi keburukan atau cenderung memberi citra yang buruk terhadap objek suatu pemberitaan. Pada artikel berita ini objek pemberitaannya berupa suatu keadaan dan tokoh. Hal ini sesuai dengan sejarah tempo yang dikenal tajam mengkritik rezim, bahkan hingga dibredel.

Seperti pada artikel berita "HidupMati Komisi antikorupsi" yang gagasan sentralnya mencitrakan keadaan buruk, usia KPK yang sedang dipertaruhkan dan keterkaitan antara nama-nama komisioner dengan revisi Undang-Undang KPK. Pada artikel berita "Jendral Polisi Sarat Kontroversi", dalam hal ini Tempo mencitrakan tokoh Firli Bahuri menuai banyak kontroversi. Pada artikel berita "Batal Istana Koreksi Hasil Seleksi", Tempo juga mencitrakan tokoh yaitu, Panitia Seleksi calon pimpinan KPK. Hal itu dapat dilihat pada elemen-elemen perangkat framing dalam setiap artikel berita.

Artikel berita "Hidup-Mati Komisi Antikorupsi" memuat dua metafora, metafora tersebut berasal dari interpretasi wartawan dan ungkapan narasumber. Artikel berita "Jendral Polisi Sarat Kontroversi" memuat metafora yang berasal dari ungkapan narasumber. Namun, dalam artikel berita ketiga, "Batal Istana Mengoreksi Hasil Seleksi", tidak terdapat elemen metafora. Metafora merupakan sebuah majas. Menurut Gunawan (2019: 7), majas dapat diartikan sebagai bahasa kias atau bahasa yang digunakan untuk menciptakan efek tertentu. Mengutip pendapat lain dari Agustinalia (2018: 3), majas metafora menggunakan kata kiasan dan terdapat pilihan kata yang menyamakan sesuatu dengan sesuatu yang lain. Berdasarkan beberapa pendapat di atas dan teori dalam sub bab materi, penulis tidak menemukan unsur metafora dalam artikel berita "Batal Istana Mengoreksi Hasil Seleksi".

Metafora yang digunakan dalam suatu artikel berita dapat lebih dari satu. Metafora tersebut dapat berasal dari hasil interpretasi wartawan maupun mengutip dari ungkapan narasumber. Meskipun 
dalam artikel berita ketiga tidak terdapat elemen metafora, namun konstruksi realitas tetap terbangun. Elemen-elemen lain saling kohesif mendukung gagasan sentral yang menjadi pokok susbtansi dalam artikel berita.

Ilustrasi yang terdapat dalam artikel berita "Hidup-Mati Komisi Antikorupsi merupakan kutipan dari ungkapan narasumber. Ungkapan tersebut secara langsung berisi ilustrasi yang mendukung gagasan sentral yang terdapat dalam artikel berita.

Ilustrasi dalam artikel berita "Jendral Polisi Sarat Kontroversi" secara langsung memuat informasi pertemuan Firli Bahuri dengan Ketua Umum Partai Demokrasi Indonesia Perjuangan. Seperti pada artikel berita pertama, ilustrasi dalam artikel berita "Batal Istana Mengoreksi Hasil Seleksi" memuat kutipan dari narasumber.

Ilustrasi dalam seluruh artikel berita, baik itu berasal dari interpretasi wartawan maupun langsung dari narasumber dimuat berdasarkan suatu tujuan, begitupun dengan informasi yang dimuat secara khusus dalam tubuh artikel berita dan ungkapan yang dipilih. Tujuan tersebut harus disesuaikan dengan gagasan sentral yang berusaha bingkai oleh suatu media.

Ketiga artikel berita dalam laporan utama majalah Tempo, mengandung kalimat atau frasa yang menonjol. Ketika terdapat suatu kalimat atau frasa yang terlihat unik atau berbeda dari yang lain, maka hal ini dapat mudah diingat bahkan tertanam dalam benak pembaca. Sehingga, apabila media akan membingkai berita, harus menggunakan elemen kontras yang benar-benar berpeluang tinggi tertanam dalam benak pembaca. Sehingga, pembaca akan merekonstruksikan hasil dari bacaannya sesuai dengan konstruksi realitas yang dimaksudkan oleh media tersebut.

Segala bentuk kontras yang dimuat dalam artikel berita digunakan untuk menekankan sebuah gagasan sentral dari masing-masing artikel berita. Sebagaimana dapat dilihat pada artikel berita "HidupMati Komisi Antikorupsi" yang elemen kontrasnya berupa kutipan dari komisioner KPK, Agus Raharjo, "Ada yang terancam dengan keberadaan KPK." Kalimat ini digunakan untuk mengkonstruksikan gagasan sentral berupa usia KPK yang sedang dipertaruhkan dan keterkaitan antara nama-nama komisioner dengan revisi Undang-Undang KPK. Hubungan antara gagasan sentral dengan elemen kontras ini adalah dimungkinkan adanya yang terancam keberadaan KPK karena adanya keterkaitan antara nama-nama komisioner dengan revisi UU KPK, sehingga dimuatlahlah ungkapan dari Agus Raharjo yang menjadi elemen kontras dalam artikel berita ini.

Artikel berita "Hidup-Mati Komisi Antikorupsi" melabeli nama Firli Bahuri dengan "tak memantik perdebatan". Padahal, Firli Bahuri tengah menjadi sorotan atas dugaan pelanggaran etik. Label yang dipilih digunakan untuk menekankan dugaan ada yang terancam dengan keberadaan KPK sehingga diaturlah sebuah strategi politik untuk mengatur KPK. Ada pihak yang berkepentingan sehingga menggunakan KPK sebagai salah satu strategi politiknya. Strategi itu dilakukan dengan cara menyiapkan namanama komisioner dan mengamankan revisi Undang-Undang KPK. Stategi politik ini dapat diketahui dari ketua KPK terpilih, meskipun tengah menjadi sorotan atas dugaan pelanggaran etik, nama Firli Bahuri sama sekali tidak menimbulkan perdebatan. Hal ini dapat dilihat dalam teks yan menjadi elemen ilustrasi pada artikel "Hidup-Mati Komisi Anikorupsi".

Teks tersebut menekankan, nama Firli Bahuri dan polemiknya terkait dugaan pelanggaran etik telah selesai, sehingga bukan masalah apabila namanya masuk ke dalam kandidat calon komisioner, bahkan mendapatkan suara penuh dari anggota fraksi di Komisi Hukum. Dengan menyebut satu-satunya nama yang tak memantik perdebatan, teks secara tidak langsung 
memberikan ruang pada pembaca untuk berpikir "ada apa dibalik ini?", karena masing-masing perwakilan fraksi telah diminta untuk menyampaikan lima nama sebagai calon komisioner KPK, sehingga forum lobi sempat memanas, nama-nama yang disampaikan setiap fraksi diperdebatkan karena berbagai alasan, namun nama Firli Bahuri sama sekali tidak dipermasalahkan.

Pada artikel berita "Jendral Polisi Sarat Kontroversi", Tempo, memberi label pada Firli Bahuri "Dekat dengan petinggi partai". Secara tidak langsung, dengan mencantumkan label ini memberikan kesan pada pembaca bahwa Firli Bahuri terpilih karena dekat dengan para petinggi partai, sehingga posisinya menjadi aman dan mempermudah jalannya untuk menjadi ketua KPK.

Artikel berita "Batal Istana Mengoreksi Hasil Seleksi”, Tempo, memberi label pada Panitia Seleksi dengan kalimat "Panitia seleksi buru-buru mengumumkannya ke publik". Secara tidak langsung, dengan mencantumkan label ini memberikan kesan pada pembaca bahwa Panitia Seleksi tidak ingin hasil penyeleksiannya dikomentari oleh para tokoh dan masyarakat.

Setiap artikel berita memiliki gagasan sentralnya masing-masing. Agar gagasan sentral tersebut sampai pada pembaca, maka digunakan elemen gambar visual. Elemen gambar visual artikel berita "Hidup-Mati Komisi Antikorupsi" menggunakan dua gambar visual. Sedangkan artikel berita "Jendral Polisi Sarat Kontroversi" dan "Batal Istana Mengoreksi Hasil Seleksi" hanya menggunakan satu gambar visual. Masingmasing gambar visual itu diberikan keterangan. Kerangan dan gambar visual yang digunakan dalam artikel berita merupakan satu kesatuan yang merujuk pada gagasan sentralnya, sehingga keduanya saling bergantung satu sama lain.

Pemilihan gambar visual pada sebuah artikel berita tentu berdasarkan maksud tertentu. Seperti yang bisa dilihat pada artikel berita "Hidup-Mati Komisi Antikorupsi", dipilih gambar visual yang menampilkan Agus Raharjo dan dua Wakil Ketua KPK dengan wajah murung. Gambar visual ini akan membuat pembaca melihat betapa Komisi Pemberantasan Korupsi sedang tidak baik-baik saja, sehingga Ketua dari lembaga antirasuah tersebut menampakkan mimik wajah dan postur tubuh tidak ceria.

Pada artikel berita "Jendral Polisi Sarat Kontroversi”, gambar visual menampilkan momen dimana Firli Bahuri sedang dalam keadaan tangan berada pada posisi hormat. Artikel berita ini fokus membahas kontroversi Firli Bahuri, sehingga dipilihlah potret Firli Bahuri dengan latar belakang bias. Pemilihan gambar visual ini, dapat membuat pembaca terfokus pada sosok Firli Bahuri dan tokoh lain yang ada dalam artikel berita menjadi bias, padahal tokoh yang disebut dalam artikel berita bukan hanya Firli Bahuri.

Seperti pada artikel berita "Jendral Polisi Sarat Kontroversi", artikel berita "Batal Istana Mengoreksi Hasil Seleksi" pun dalam elemen gambar visualnya menonjolkan tokoh. Pada artikel berita ini, tokoh yang ditampilkan adalah Panitia Seleksi Calon Pimpinan KPK, tokoh-tokoh lain yang juga terdapat dalam artikel berita ini menjadi terbiaskan.

\section{KESIMPULAN DAN IMPLIKASI}

\section{KESIMPULAN}

Perangkat framing model Gamson dan Modigliani tentang pemberitaan Komisi Pemberantasan Korupsi pada laporan utama majalah Tempo edisi 4524/16-22 September 2019, memuat konstruksi citra model bad news. Elemen metafora yang digunakan pada artikel berita 1 adalah "Hidup-Mati" dan "di ujung tanduk, pada artikel berita 2 menggunakan metafora "kami melakukan pengamanan", pada artikel berita 3 tidak menggunakan elemen metafora. Elemen ilustrasi pada artikel berita 1 memuat "nama Firli Bahuri tidak memantik perdebatan", pada artikel berita 2 ilustrasi memuat "pertemuan Firli 
dengan Ketua Umum Partai Demokrasi Indonesia Perjuangan (PDIP) beserta rombongan", pada artikel 3 berita memuat ilustrasi berupa "ungkapan Presiden Jokowi sebelum menggelar pertemuan tertutup dengan anggota Panitia Seleksi". Kontras pada artikel berita 1 adalah "ada yang terancam dengan keberadaan KPK", pada artikel berita 2 menggunakan kontras berupa "meskipun menjadi kandidat yang menuai kontroversi, namun Firli terpilih sebagai ketua KPK", kontras pada artikel berita 3 adalah "Batal istana mengoreksi hasil seleksi". Label pada artikel berita 1 berupa "tak memantik perdebatan", pada artikel berita 2 label berupa "Dekat dengan petinggi partai", pada artikel berita 3 menggunakan label berupa "Pansel buru-buru mengumumkan ke publik". Gambar visual pada artikel berita 1 menunjukan papan perhitungan suara pemilihan komisioner KPK yang sedang diambil gambarnya oleh peserta rapat dan Agus Rahardjo beserta dua Wakil Ketua KPK sedang memberikan keterangan dengan wajah murung, pada artikel berita 2 menunjukan gambar Firli Bahuri, dan artikel berita 3 menunjukan potret Anggota Panitia Seleksi calon pimpinan KPK.

\section{IMPLIKASI TEORITIS}

Perangkat framing model Gamson dan Modigliani digunakan Tempo dalam mengkonstruksikan artikel berita. Hal ini ditunjukkan di dalam laporan utama majalah Tempo edisi 4524/16-22 September 2019. Artikel berita "HidupMati Komisi Antikorupsi" dan artikel berita "Jendral Polisi Sarat Kontroversi" memenuhi seluruh elemen-elemen yang terdapat dalam perangkat framing, namun artikel berita "Batal Istana Mengoreksi Hasil Seleksi", tidak memenuhi salah satu elemen dalam perangkat framing, yaitu metafora. Meskipun dalam artikel berita ketiga tidak terdapat elemen metafora, namun konstruksi realitas tetap terbangun. Elemen-elemen lain saling kohesif mendukung gagasan sentral yang menjadi pokok susbtansi dalam artikel berita.

\section{IMPLIKASI PRAKTIS}

Hasil penelitian ini dapat digunakan sebagai salah satu bahan masukan bagi pelaku media dalam mengkonstruksikan realitas melaui framing berita. Selain itu, penelitian ini juga dapat memberi masukan kepada publik agar dapat lebih kristis dalam memaknai pemberitaan yang disuguhkan oleh media massa, sehingga dapat membentuk sikap bijaksana dari terpaan media massa, karena setiap media mengkonstruksi berita dengan konstruksinya masing-masing. Fakta yang disajikan dalam berita dipilih sesuai dengan konstruksi yang akan diciptakan oleh media.

\section{DAFTAR PUSTAKA}

\section{Naskah jurnal.}

El-nawawy Mohammed, Elmasry Mohamad Hamas. 2017. Valuing Victim: A Comparative Framing Analysis of The Washington Post's Coverage of Violent Attacks Against Muslimsnand NonMuslims. International Journal of Communication. 11: 1795-1815.

Ramandita, Rr Ranti dan Yuliana, Gati Dwi. 2018. Undang-undang Antikorupsi dalam Bingkai Konstruksi Media. Jurnal IImu Komunikasi. 16 (1): 15-30.

\section{Buku.}

Agustinalia, Irma. 2018. Majas, Idiom, dan Peribahasa Indonesia. CV Graha Printama Selaras. Sukoharjo.

Ardianto, Elvaniro dkk. 2017. Komunikasi Massa Suatu Pengantar Edisi Revisi. Simbiosis Rekatama Media. Bandung.

Atmaja, Bawa Nengah dan Ariyani, Luh Putu Sri. 2018. Sosiologi Media: Perspektif Teori Kritis. Rajawali Pers. Depok.

Eriyanto. 2012. Analisis Framing: Konstruksi, Ideologi, dan Politik Media. LkiS Group. Yogyakarta.

Gunawan, Haadi. 2019. Majas dan Peribahasa. Cosmic Media Nusantara. Jogjakarta.

Sobur, Alex. 2015. Analisis Teks Media Suatu Pengantar untuk Analisis Wacana, 
Analisis Semiotik, dan Analisis Framing. PT Remaja Rosdakarya. Bandung.

Tamburaka, Apriadi. 2012. Agenda Setting Media Massa. PT Rajagrafindo Persada. Jakarta.

Vardiansyah, Dani dan Febriani, Erna. 2018. Filsafat Ilmu Komunikasi Pengantar Ontologi, Epistemologi, Aksiologi. Indeks Jakarta. Jakarta.

\section{Majalah}

Ferdianto, Riki dkk. 2019. Hidup-Mati Komisi Antikorupsi. Majalah Tempo. Edisi 16-22 September 2019, halaman 70-73. Jakarta.

Trianita, Linda. 2019. Jenderal Polisi Sarat Kontroversi. Majalah Tempo. Edisi 16-22 September 2019, halaman 74-75. Jakarta. 